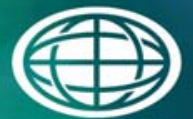

Savannah River

National Laboratory ${ }^{m}$

OPERATED BY SAVANNAH RIVER NUCLEAR SOLUTIONS

\title{
Saltstone Osmotic Pressure
}

\author{
Ralph L. Nichols
}

Kenneth L. Dixon

September 2013

SRNL-STI-2013-00533 
SRNL-STI-2013-00533

Revision 0

\section{DISCLAIMER}

This work was prepared under an agreement with and funded by the U.S. Government. Neither the U.S. Government or its employees, nor any of its contractors, subcontractors or their employees, makes any express or implied:

1. warranty or assumes any legal liability for the accuracy, completeness, or for the use or results of such use of any information, product, or process disclosed; or

2. representation that such use or results of such use would not infringe privately owned rights; or

3. endorsement or recommendation of any specifically identified commercial product, process, or service.

Any views and opinions of authors expressed in this work do not necessarily state or reflect those of the United States Government, or its contractors, or subcontractors.

\section{Printed in the United States of America \\ Prepared for \\ U.S. Department of Energy}


Keywords: Saltstone, osmosis, salt, radioactive waste, permeameter

Retention: Permanent

\section{Saltstone Osmotic Pressure}

Ralph L. Nichols

Kenneth L. Dixon

September 2013

Prepared for the U.S. Department of Energy under 
SRNL-STI-2013-00533

Revision 0 
SRNL-STI-2013-00533

Revision 0

\section{EXECUTIVE SUMMARY}

Recent research into the moisture retention properties of saltstone suggest that osmotic pressure may play a potentially significant role in contaminant transport (Dixon et al., 2009 and Dixon, 2011). The Savannah River Remediation Closure and Disposal Assessments Group requested the Savannah River National Laboratory (SRNL) to conduct a literature search on osmotic potential as it relates to contaminant transport and to develop a conceptual model of saltstone that incorporates osmotic potential. This report presents the findings of the literature review and presents a conceptual model for saltstone that incorporates osmotic potential. The task was requested through Task Technical Request HLW-SSF-TTR2013-0004.

Simulated saltstone typically has very low permeability (Dixon et al. 2008) and pore water that contains a large concentration of dissolved salts (Flach and Smith 2013). Pore water in simulated saltstone has a high salt concentration relative to pore water in concrete and groundwater. This contrast in salt concentration can generate high osmotic pressures if simulated saltstone has the properties of a semipermeable membrane. Estimates of osmotic pressure using results from the analysis of pore water collected from simulated saltstone show that an osmotic pressure up to 2790 psig could be generated within the saltstone. Most semi-permeable materials are non-ideal and have an osmotic efficiency $<1$ and as a result actual osmotic pressures are less than theoretical pressures.

Observations from laboratory tests of simulated saltstone indicate that it may exhibit the behavior of a semi-permeable membrane. After several weeks of back pressure saturation in a flexible wall permeameter (FWP) the membrane containing a simulated saltstone sample appeared to have bubbles underneath it. Upon removal from the FWP the specimen was examined and it was determined that the bubbles were due to liquid that had accumulated between the membrane and the sample. One possible explanation for the accumulation of solution between the membrane and sample is the development of osmotic pressure within the sample.

Osmotic pressure will affect fluid flow and contaminant transport and may result in the changes to the internal structure of the semi-permeable material. Bénard et al. 2008 reported swelling of wet cured Portland cement mortars containing salts of $\mathrm{NaNO}_{3}, \mathrm{KNO}_{3}, \mathrm{Na}_{3} \mathrm{PO}_{4} \mathrm{x} 12 \mathrm{H}_{2} \mathrm{O}$, and $\mathrm{K}_{3} \mathrm{PO}_{4}$ when exposed to a dilute solution. Typically hydraulic head is considered the only driving force for groundwater in groundwater models. If a low permeability material containing a concentrated salt solution is present in the hydrogeologic sequence large osmotic pressures may develop and lead to misinterpretation of groundwater flow and solute transport. The osmotic pressure in the semi-permeable material can significantly impact groundwater flow in the vicinity of the semi-permeable material. One possible outcome is that groundwater will flow into the semi-permeable material resulting in hydrologic containment within the membrane. Additionally, hyperfiltration can occur within semi-permeable materials when water moves through a membrane into the more concentrated solution and dissolved constituents are retained in the lower concentration solution.

Groundwater flow and transport equations that incorporate chemical gradients (osmosis) have been developed. These equations are referred to as coupled flow equations. Currently groundwater modeling to assess the performance of saltstone waste forms is conducted using the PORFLOW groundwater flow and transport model. PORFLOW does not include coupled flow from chemico-osmotic gradients and therefore numerical simulation of the effect of coupled flow on contaminant transport in and around saltstone cannot be assessed. Most natural semi-permeable membranes are non-ideal membranes and do not restrict all movement of solutes and as a result theoretical osmotic potential is not realized. Osmotic efficiency is a parameter in the coupled flow equation that accounts for the non-ideal behavior of most 
semi-permeable membranes. On order to evaluate the effects of osmotic potential on the hydraulic of a system the osmotic potential must be known. Several lab methods have been developed to measure osmotic efficiency for use in coupled flow analysis. 


\section{TABLE OF CONTENTS}

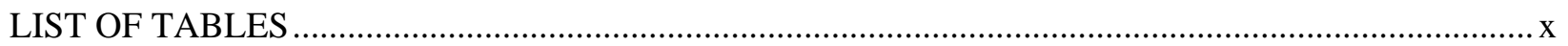

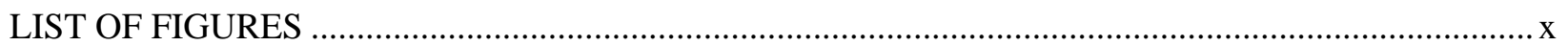

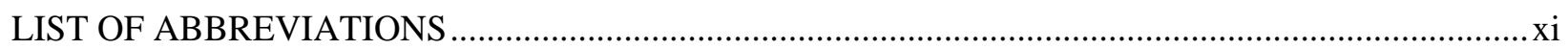

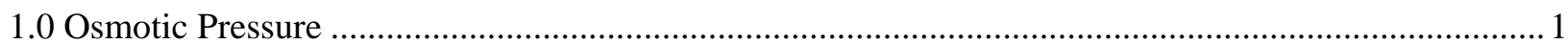

2.0 Naturally Occurring Semi-permeable Materials ..........................................................................

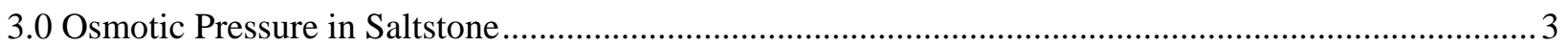

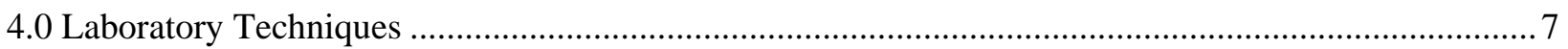

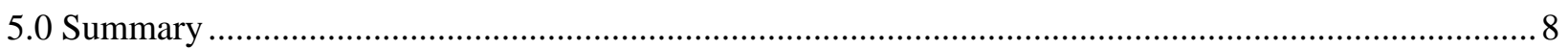

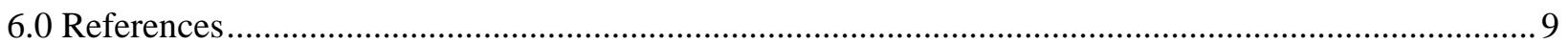




\section{LIST OF TABLES}

Table 1 Molar concentration of solutes in pore water from concrete, saltstone simulant, and groundwater. .

Table 2 Estimated equilibrium osmotic pressures in concrete and saltstone. .............................................. 5

\section{LIST OF FIGURES}

Figure 1 Osmotic equilibrium developed across an ideal semi-permeable membrane and in an ideal semipermeable material.

Figure 2 Conceptual model of saltstone for estimating equilibrium osmotic pressure.............................. 4

Figure 3 Equilibrium osmotic pressure for individual constituents in salt and pore water from simulated

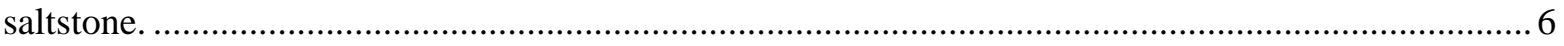

Figure 4 Saltstone sample in flexible wall permeameter showing pickled surface. …............................. 7

Figure 5 Typical configuration of a permeameter for measuring osmotic efficiency................................ 8 


\section{LIST OF ABBREVIATIONS}

$\begin{array}{ll}\text { SRNL } & \text { Savannah River National Laboratory } \\ \text { TDS } & \text { Total Dissolved Solids } \\ \text { MCU } & \text { Modular Caustic Side Solvent Extraction } \\ \text { mol/L } & \text { moles per liter } \\ \text { FWP } & \text { Flexible Wall Permeameter } \\ \text { atm } & \text { atmosphere } \\ \text { SRS } & \text { Savannah River Site } \\ \text { psig } & \text { pounds per square inch gauge } \\ \text { Mpa } & \text { Mega pascal } \\ \text { PA } & \text { Performance Assessment }\end{array}$




\subsection{Osmotic Pressure}

Osmotic pressure results from a difference in the free energy of solutions separated by a semipermeable membrane. The dissolution of salts into a solvent (water) creates a solution that has a lower free energy than the original solute. Free energy can also be decreased by increasing the temperature of a solute or decreasing the hydrostatic pressure on a solute. An ideal semipermeable material is a material that has pores small enough to prevent movement of any solute but large enough to pass molecules of the solvent. The exclusion of solutes can result from pore size exclusions or electrical exclusions.

Solute movement through pores can be prevented by physical size constraints due to small pore diameters or repulsion of solutes with a charge the same as the charge on the surface of the membrane. Typical cement paste has a very high $\mathrm{pH}$ and $\mathrm{C}-\mathrm{S}-\mathrm{H}$ particles become highly negatively charged due to titration of the silanol groups, Bénard et. al 2008. Divalent calcium ions in the solution are attracted to the negative surface and counterbalance the negative charge resulting in a positively charged double layer around the particles. This double layer effectively reduces the pore size and can restrict the movement of positive ions though small pore throats. Richet 1992 reported a diffusion coefficient for tritiated water 2x greater than cesium at high W/C ratios.

When a solvent is separated from a solution by a semi-permeable membrane, solvent will flow through the semi-permeable membrane into the solution reducing the concentration of the solution, this is referred to as chemical osmosis (osmosis). The solution initially has lower free energy than the solvent and the system is not in equilibrium. This difference in free energy between the solvent and the solution results in the flow of solvent through the semi-permeable membrane into the solution decreasing the concentration (increasing free energy) of the solution and increasing the pressure on the solution side as the liquid level rises, Figure 1 . Both decreasing solution concentration and increasing pressure increases the free energy on the solution side of the semi-permeable membrane. Flow will continue until the free energy on both sides of the semi-permeable membrane is equal.

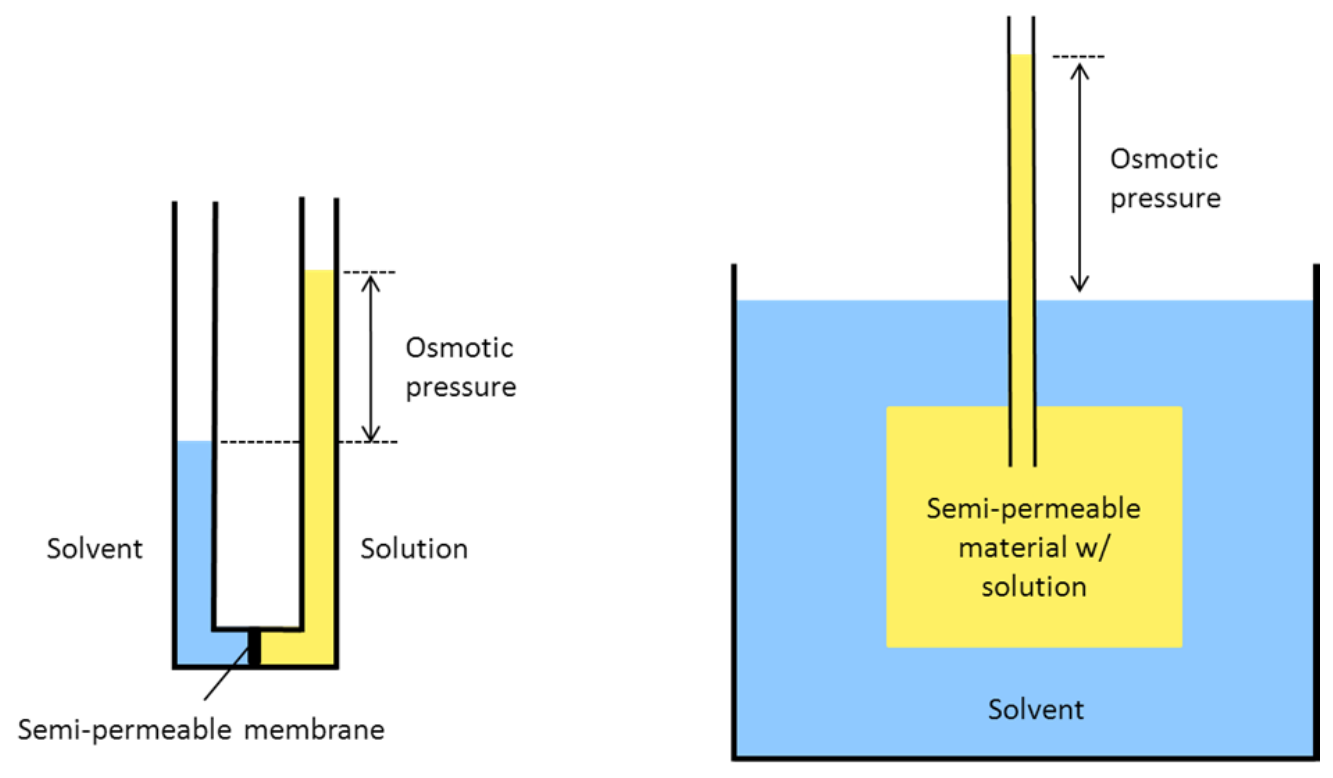

Figure 1 Osmotic equilibrium developed across an ideal semi-permeable membrane and in an ideal semi-permeable material. 
Similarly when a solution is contained within a semi-permeable material surrounded by a solvent pressure will increase within the semi-permeable material until the free energy inside and outside the semi-permeable material is in equilibrium, Figure 1 . The flow in semi-permeable membranes/materials is very slow because they are typically fine grained and have small pores. The final pressure difference when flow has stopped across an ideal semi-permeable membrane is known as "osmotic pressure". When a salt is dissolved in water the resulting ions become surrounded by a shell of water molecules (solvated) creating a solute that has a larger diameter than the solvent or the ion. Many natural materials that exhibit membrane behavior such as clays have small pores and pore throats that are large enough to transmit solvated ions. However, laboratory studies show that some of these clays preferentially transmit water and exclude salt. This exclusion is due to electrical charges on the surface of the clay particle, the double layer, which effectively reduces the size of the pore preventing the solvated ions salt from being transmitted (Marine and Fritz 1981).

Osmotic pressure $(\pi)$ is a colligative property and depends solely on the ratio of the number of particles of solute to the number of solvent molecules in a solution and has nothing to do with the chemical behavior of the solute. Osmotic pressure for a solution can be related to total pressure $(P)$ and capillary or matric pressure $\left(P_{c}\right)$ using the following equation:

$$
P=P_{c}+\pi
$$

where

$$
\pi=\left(\frac{R T}{V_{w}}\right) \ln \left(\frac{P_{A}^{0}}{P_{A}}\right)
$$

$R$ is the gas constant, $T$ is temperature, $V_{w}$ is molar volume of water and $P_{A}^{0}$ and $P_{A}$ are the vapor pressure of the solute in the dilute and concentrated solutions (Neuzil and Provost 2009, AlBazali 2012). The osmotic pressure difference across an ideal semi-permeable membrane can be calculated in terms of the difference in concentration of individual solutes (Malusis et al. 2001) using the following equation

$$
\Delta \pi=R T \sum_{i=1}^{N} \Delta C_{i}
$$

where $\Delta C_{i}$ represents the concentration difference of solute $i$ across the membrane.

Most semi-permeable membranes are non-ideal due to heterogeneity in pore sizes and the development of micro-cracks. A parameter, membrane efficiency $(\sigma)$, is used to characterize this non-ideality. When the pressure in an osmotic system is in equilibrium $\sigma$ is defined as:

$$
\sigma=\left(\frac{\Delta P}{\Delta \pi}\right) \text { when } J_{v}=0
$$

where $\Delta P$ is the actual observed osmotic pressure and $\Delta \pi$ is the ideal osmotic pressure. Neuzil and Provost 2009 present results from the analysis of 18 different geologic materials using both lab and in-situ tests to estimate $\sigma$. They found $\sigma$ to range from 0.0004 to 1.0 and concluded a better understanding of geological membranes and their ability to generate osmotic pressures will require more extensive experimental characterization of their properties than has been attempted thus far. 
Fluid flow that is in response to a chemical gradient in addition to a hydraulic head gradient is said to be coupled flow. Darcy's law for fluid flow can be written in a generalized form to include fluid flow due to osmosis as follows:

$$
q=-\frac{k}{\mu}(\nabla p+\rho g \nabla z)+\sigma \frac{k}{\mu} \nabla \pi
$$

where $q=$ is Darcy flux of pore fluid, $k$ is permeability, $\mu$ is dynamic viscosity, $g$ is gravitational constant, $\sigma$ is osmotic efficiency $\pi$ is ideal osmotic pressure (Neuzil and Provost 2009). The first term accounts for flow due to hydraulic head gradient and the second term accounts for osmosis. $\sigma$, the osmotic efficiency term, was introduced to account for non-ideal behavior nature of semipermeable membranes in nature. The current version of PORFLOW that SRNL uses for Performance Assessment (PA) of saltstone disposal does not include coupled flow from chemicoosmotic potentials.

\subsection{Naturally Occurring Semi-permeable Materials}

There are many natural occurrences where osmotic pressure is used as a driving force for fluid in a permeable material. Plants use osmotic pressure to transport water into and out of cells, roots use osmotic pressure to draw water from soil, and kidneys use osmotic pressure as part of the filtration system for blood. Additionally there are occurrences of geologic sequences containing fluids of different salinities resulting in large osmotic pressures. Neuzil 2000 reported results from a 9 year in-situ measurement of fluid pressures and solute concentrations in the Cretaceousage Pierre shale that are consistent with the generation of large (20 Mpa, 2900 psig) osmotic pressure anomalies which could persist for 10 s of millions of years. The Pierre shale has a permeability of $\sim 10 \mathrm{E}-18$ darcy and shale pore water contains $\sim 3.5 \mathrm{~g} / \mathrm{L} \mathrm{NaCl}$ with only minor amounts of other solutes.

Anomalous subsurface hydraulic pressures up to 750 psig were observed in the buried sediments of the Dunbarton Triassic Basin at the Savannah River Site near Aiken, SC. Water levels in groundwater wells installed in the Dunbarton Basin were $100 \mathrm{~m}$ meters above the water level in groundwater wells in the overlying coastal plain aquifer (Marine 1974). Marine and Fritz 1981 showed that the most likely explanation for the anomalous water levels is osmotic pressure. The mudstone sediments of the Dunbarton Basin are comprised predominately of illite a very low permeability material (5E-8 darcy) and contain pore water with a TDS of $\sim 10,000 \mathrm{mg} / \mathrm{L}$ as compared to the groundwater in the overlying sandy coastal plain aquifer with $\sim 40 \mathrm{mg} / \mathrm{L} \mathrm{TDS}$.

\subsection{Osmotic Pressure in Saltstone}

Saltstone is a low permeability porous waste form made from Portland cement, slag, fly ash and low-level salt waste (salt). Salt is a solution containing primarily, sodium, nitrate, and hydroxide along with other minor constituents and radioactive material. Table 1 lists the primary constituents in groundwater (A), pore water in two different concrete mixtures (B1 and B2 used for saltstone vault construction), and saltstone simulant (C). 
SRNL-STI-2013-00533

Revision 0

Table 1 Molar concentration of solutes in pore water from concrete, saltstone simulant, and groundwater.

\begin{tabular}{c|c|c|c|c}
\hline & \multicolumn{4}{|c}{ Solute concentration in pore water (mol/L) } \\
& a Groundwater & ${ }^{\mathrm{b}}$ SDU2 & ${ }^{\mathrm{b}} \mathrm{SDU} 1 / 4$ & ${ }^{\mathrm{b}}$ Sim 1 \\
Solute & $\mathrm{A}$ & $\mathrm{B} 1$ & $\mathrm{~B} 2$ & $\mathrm{C}$ \\
\hline $\mathrm{Na}$ & $9.8 \mathrm{E}-05$ & $2.7 \mathrm{E}-02$ & $7.4 \mathrm{E}-02$ & $4.1 \mathrm{E}+00$ \\
\hline $\mathrm{NO}_{3}$ & $6.4 \mathrm{E}-05$ & $\mathrm{~nm}$ & $\mathrm{~nm}$ & $3.6 \mathrm{E}+00$ \\
\hline $\mathrm{OH}$ & $1.7 \mathrm{E}-10$ & $1.1 \mathrm{E}-01$ & $2.4 \mathrm{E}-01$ & $3.8 \mathrm{E}-01$ \\
\hline $\mathrm{CO}_{3}$ & $6.4 \mathrm{E}-04$ & $\mathrm{~nm}$ & $\mathrm{~nm}$ & $4.7 \mathrm{E}-02$ \\
\hline $\mathrm{SO}_{4}$ & $2.7 \mathrm{E}-05$ & $1.0 \mathrm{E}-04$ & $<1.0 \mathrm{E}-04$ & $1.1 \mathrm{E}-01$ \\
\hline $\mathrm{K}$ & $8.6 \mathrm{E}-06$ & $3.6 \mathrm{E}-02$ & $1.4 \mathrm{E}-01$ & $1.2 \mathrm{E}-01$ \\
\hline $\mathrm{Ca}$ & $7.4 \mathrm{E}-05$ & $2.0 \mathrm{E}-03$ & $2.0 \mathrm{E}-03$ & $1.0 \mathrm{E}-04$ \\
\hline $\mathrm{Cl}$ & $1.2 \mathrm{E}-04$ & $4.0 \mathrm{E}-03$ & $5.0 \mathrm{E}-03$ & $1.2 \mathrm{E}-02$ \\
\hline $\mathrm{Sum}$ & $1.0 \mathrm{E}-03$ & $1.8 \mathrm{E}-01$ & $4.7 \mathrm{E}-01$ & $8.4 \mathrm{E}+00$ \\
\hline
\end{tabular}

Note:

$\mathrm{nm}=$ not measured

${ }^{\mathrm{a}}=$ (Millings and Denham 2012)

$\mathrm{b}=$ (Flach and Smith 2013)

Equilibrium osmotic pressures were estimated for the saltstone model in Figure 2 using Equation 2 and assuming that the concrete and saltstone act as ideal semi-permeable membranes, Table 2. SDU 2 and SDU1/4 represent different concrete formulations in disposal unit construction at the Savannah River Site (SRS). Low osmotic pressures, 63 - 162 psig, will develop in the concrete due to the dilute nature of the pore water in concrete, $0.2-0.5 \mathrm{~mol} / \mathrm{L}$. This means that if the concrete acts as an ideal semi-permeable membrane, over time pore pressure could build up to 63 - 162 psig in the concrete due to coupled water flow from the surrounding sediment into the concrete.

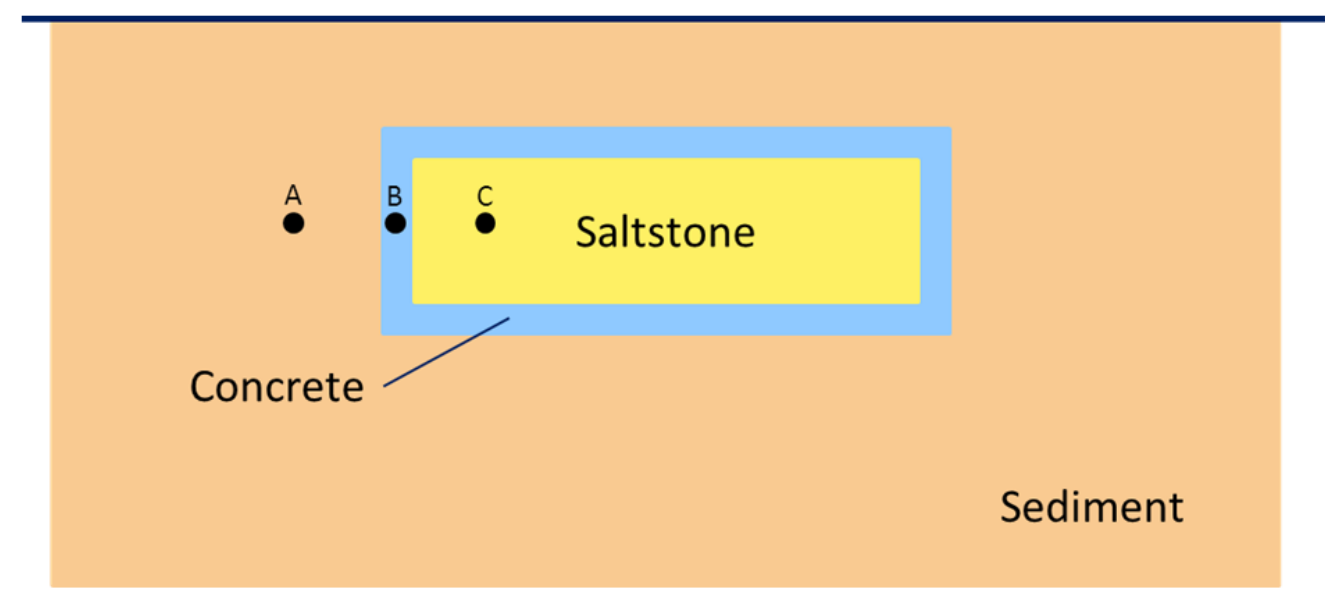

Figure 2 Conceptual model of saltstone for estimating equilibrium osmotic pressure. 
Equation 3 was also used to estimate the equilibrium osmotic pressure in saltstone if it acts as an ideal semi-permeable membrane, Table $2 . \mathrm{Na}, \mathrm{NO}_{3}$ and $\mathrm{OH}$ are the primary solutes contributing to the osmotic pressure. Osmotic pressure in the saltstone is estimated to reach 2790 psig. Figure 3 illustrates the osmotic pressure from individual solutes in salt and pore water. Under these conditions water would continue to flow from the sediment through the concrete and into saltstone until the pore pressure in the saltstone reached $\sim 2790$ psig. Due to the low permeability of the concrete and saltstone equilibrium would likely require years. Neuzil 2000 reported results from field observations that showed that after nine years the water level in a groundwater well had still not equilibrated with the surrounding sediment.

Table 2 Estimated equilibrium osmotic pressures in concrete and saltstone.

\begin{tabular}{c|c|c|c|c}
\hline & \multicolumn{4}{|c}{ Equilibrium osmotic pressure (psig) } \\
& SDU2-GW & SD 1/4-GW & Sim 1-SDU2 & Sim1-SDU 1/4 \\
Solute & A/B1 & A/B2 & B1/C & B2/C \\
\hline $\mathrm{Na}$ & 9.35 & 25.70 & 1431.60 & 1415.26 \\
\hline $\mathrm{NO}_{3}$ & -0.02 & -0.02 & 1235.13 & 1235.13 \\
\hline $\mathrm{OH}$ & 39.64 & 84.85 & 93.89 & 48.68 \\
\hline $\mathrm{CO}_{3}$ & -0.22 & -0.22 & 16.27 & 16.27 \\
\hline $\mathrm{SO}_{4}$ & -0.01 & -0.01 & 38.84 & 38.84 \\
\hline $\mathrm{K}$ & 12.52 & 49.03 & 29.56 & -6.95 \\
\hline $\mathrm{Ca}$ & 0.67 & 0.67 & -0.70 & -0.70 \\
\hline $\mathrm{Cl}$ & 1.35 & 1.70 & 2.75 & 2.40 \\
\hline Total & 63.28 & 161.68 & 2847.34 & 2748.94 \\
\hline
\end{tabular}

Figure 4 is a photograph of a saltstone simulant in a flexible wall permeameter (FWP) with confining pressure of 60 psig and pore pressure of 54 psig. After several weeks of back pressure saturation with water, blisters were observed on the membrane containing the saltstone sample. The saltstone sample was examined upon removal from the FWP and it was determined that the blisters observed on the surface were due to liquid that had accumulated between the membrane and the sample. One possible explanation for the accumulation of solution between the membrane and sample is the development of osmotic pressure within the sample. If the saltstone acts as a semi-permeable membrane, the difference in concentration of solutes in salt in the pores of the saltstone and the water permeant could result in the flow of water into the sample due to the osmotic pressure gradient. Flow of water into the sample due to osmotic pressure would increase the pressure in the sample expelling solution into the space between the membrane and the sample. It is important to note that at this time the sample was undergoing back pressure saturation and there was no pressure gradient applied across the sample. 


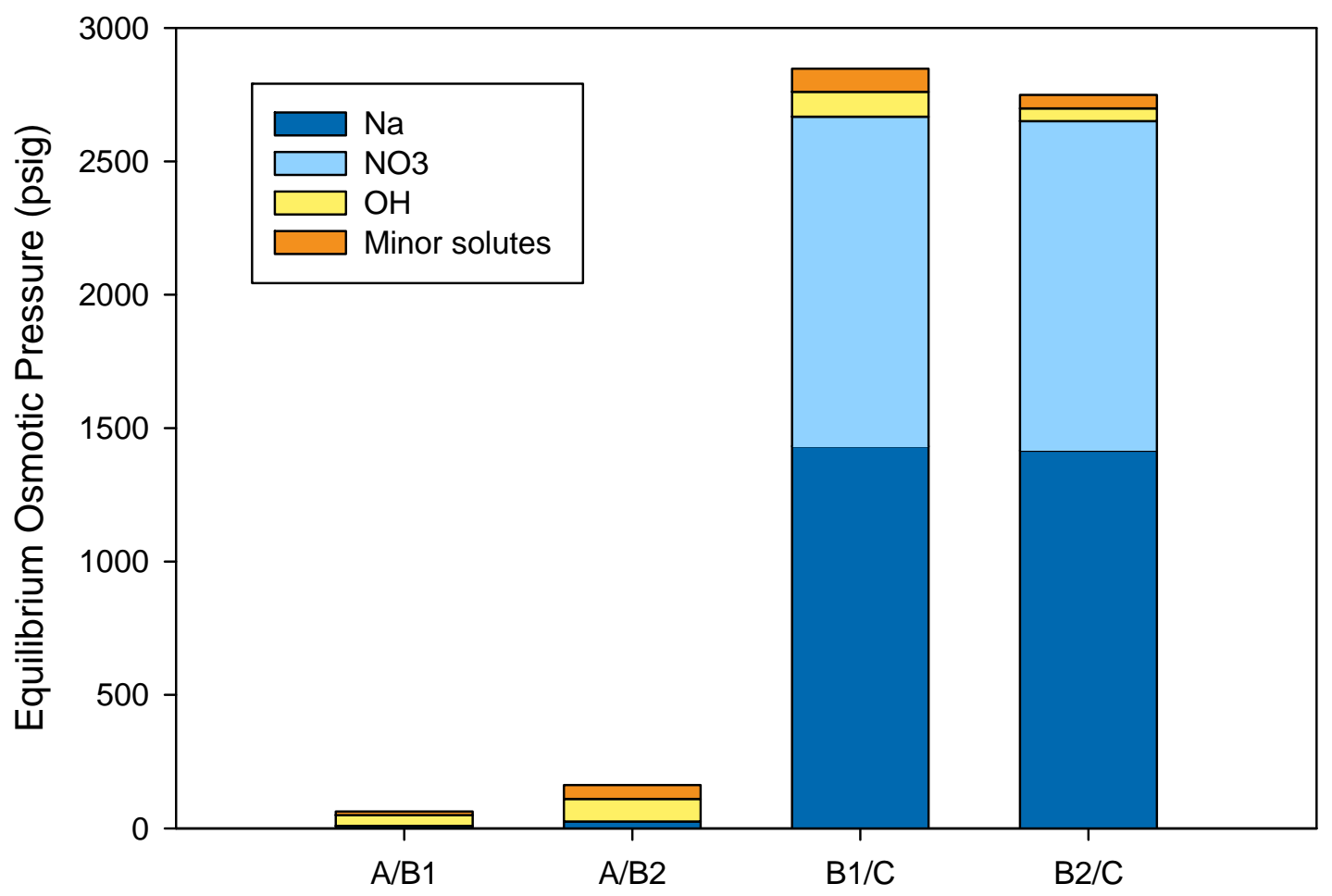

Figure 3 Equilibrium osmotic pressure for individual constituents in salt and pore water from simulated saltstone.

Osmotic pressure will affect groundwater flow and transport and may result in the changes to the internal structure of the membrane. Typically hydraulic head is considered the only driving force for groundwater in groundwater models. If a low permeability material containing a concentrated salt solution is present in the hydrogeologic sequence large osmotic pressures may develop and lead to misinterpretation of groundwater flow and solute transport. The osmotic pressure in the semi-permeable material can significantly impact groundwater flow in the vicinity of the semipermeable material. One possible outcome is that groundwater will flow into the semi-permeable material resulting in hydrologic containment within the membrane. Additionally, hyperfiltration can occur within semi-permeable materials when water moves through a membrane into the more concentrated solution and dissolved constituents are retained in the lower concentration solution. Graf et al. 1965 and Coplen and Hanshaw 1975 report that the isotopic composition of water and dissolved constituents was altered by a geologic membrane.

Osmosis can lead to swelling and structural modification of membranes when water is drawn into the membrane by osmotic pressure. Horeseman et al. 2007 reported swelling of a claysale material after exposure to a fluid with $1 / 2$ the theoretical $\pi$ of pore fluid in the clayshale. Exposure of bituminized $\mathrm{NaNO}_{3}$ radioactive waste simulant to fluid resembling pore water in concrete for 4 years resulted in swelling of between 10\%-20\% (Valcke et al 2010). Bénard et al. 2008 reported swelling of wet cured Portland cement mortars containing salts of $\mathrm{NaNO}_{3}, \mathrm{KNO}_{3}$, $\mathrm{Na}_{3} \mathrm{PO}_{4} \mathrm{x} 12 \mathrm{H}_{2} \mathrm{O}$, and $\mathrm{K}_{3} \mathrm{PO}_{4}$ when exposed to a dilute solution. 


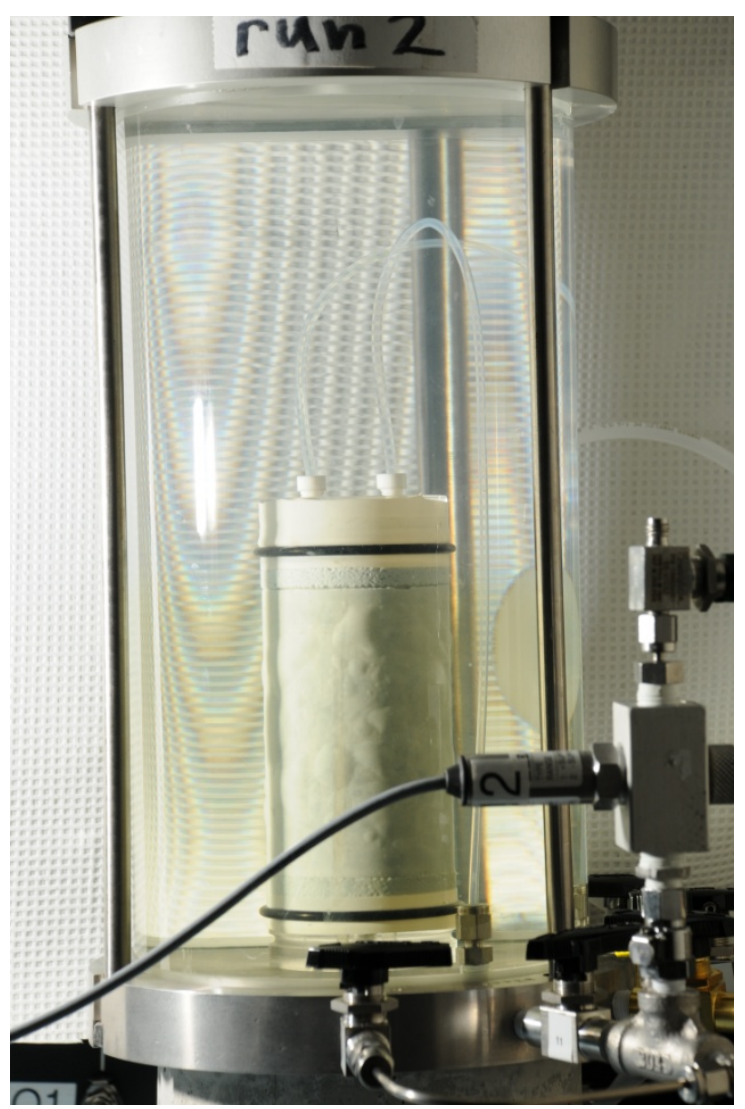

Figure 4 Saltstone sample in flexible wall permeameter showing pickled surface.

\subsection{Laboratory Techniques}

Experimental methods have been developed to estimate the osmotic efficiency of a material suspected to have the properties of a semi-permeable membrane (Gonçlavès 2008, Malusis et al. 2001, Keijzer et al. 1999, Gonçlavès et al. 1999, Houbenand and Wagner 2007, Horseman et al. 2007, and Valcke et al. 2010). The methods generally resemble each other in their configuration. A sample is placed in a permeameter similar to the one in Figure 5 . The end caps allow application of backpressure and circulation of fluid across both ends of the sample. The molarity of the circulating fluid is selected based on the concentration of the pore water in the semipermeable material and the type of test being conducted. This equipment is similar to the FWP already operated by SRNL. Sensors can be added to one of the end caps to measure stress or stain if desired to study structural changes to the semi-permeable material. 


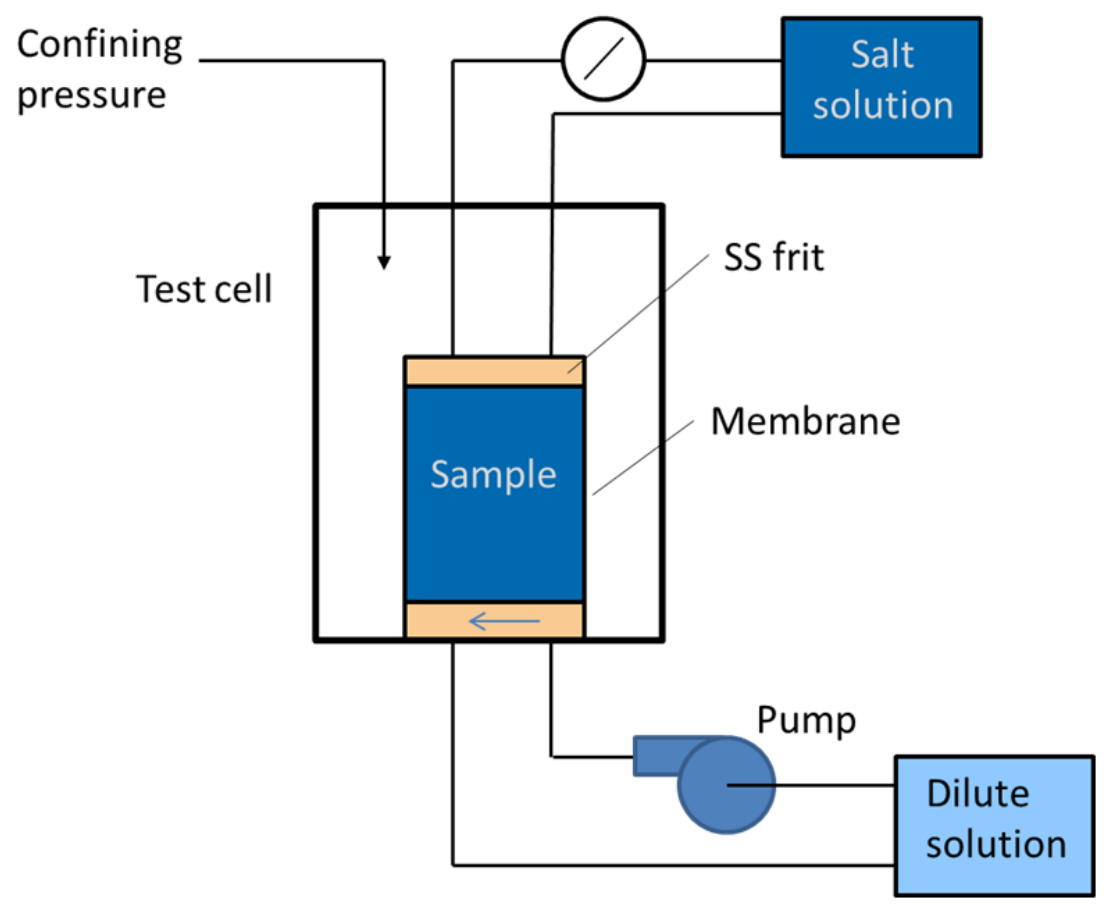

Figure 5 Typical configuration of a permeameter for measuring osmotic efficiency.

\subsection{Summary}

Simulated saltstone typically has very low permeability (Dixon et al. 2008) and pore water that contains a large concentration of dissolved salt (Flach and Smith 2013). Pore water in simulated saltstone has a higher salt concentration relative to pore water in concrete and groundwater. This contrast in molarity can generate high osmotic pressures if simulated saltstone has the properties of a semi-permeable membrane. Observations from laboratory tests of simulated saltstone indicate that it may exhibit the behavior of a semi-permeable membrane. Estimates of osmotic pressure using results from pore water analysis show that osmotic pressure up to 2790 psig could be generated within the saltstone. Most semi-permeable materials are non-ideal and have an osmotic efficiency $<1$ and as a result actual osmotic pressures are less than theoretical pressures.

Osmotic pressure will affect fluid flow and contaminant transport and may result in the changes to the internal structure of the membrane. Typically hydraulic head is considered the only driving force for groundwater in groundwater models. If a low permeability material containing a concentrated salt solution is present in the hydrogeologic sequence large osmotic pressures may develop and lead to misinterpretation of fluid flow and solute transport. The osmotic pressure in the semi-permeable material can significantly impact groundwater flow in the vicinity of the semi-permeable material. One possible outcome is that groundwater will flow into the semipermeable material resulting in hydrologic containment within the membrane. Additionally, hyperfiltration can occur within semi-permeable materials when water moves through a membrane into the more concentrated solution and dissolved constituents are retained in the lower concentration solution. Graf et al. 1965 and Coplen and Hanshaw 1975 report that the isotopic composition of water and dissolved constituents was altered by a geologic membrane.

Groundwater flow and transport equations that incorporate chemical gradients (osmosis) have been developed. These equations are referred to as coupled flow equations. PORFLOW does not 
currently include coupled flow from chemico-osmotic gradients and therefore numerical simulation of the effect of coupled flow could not be performed. Osmotic efficiency is a parameter in the coupled flow equation that is not typically measured because coupled flow is not commonly encountered. Several lab methods have been developed to measure osmotic efficiency for use in coupled flow analysis.

\subsection{References}

Al-Bazali, T.M. 2012. The consequences of using concentrated salt solutions for mitigating wellbore instability in shales. Journal of Petroleum Sciences and Engineering 80:94-101.

Bénard, P., C Cau Dit Coumes, S. Garrault, A. Nonat, and S. Courtis. 2008. Dimensional stability under wet curing of mortars containing high amounts of nitrates and phosphates. Cement and Concrete Research 38:1181-1189.

Coplen, T. B. and B. B. Hanshaw. 1973. Ultrafiltration by a compacted clay membrane, 1 Oxygen and hydrogen isotopic fractionation, Geochim Cosmochim. ACTA. 73:2295-2310.

Dixon K. L., J. Harbour and M A. Phifer. 2008. Hydraulic and Physical Properties of Saltstone Grouts and Vault Concretes, SRNL-STI-2001-00421 Rev. 0. Aiken, SC: Savannah River Nuclear Solutions.

Dixon, K. L. 2011. Moisture Retention Properties of High Temperature Cure Arp/MCU Saltstone Grout. SRNL-STI-2011-00661, Rev. 0. Aiken, SC, Savannah River Nuclear Solutions, Aiken, SC.

Domenico, P. A. and F. W. Schwartz. 1990. Physical and Chemical Hydrogeology. New York: John Wiley \& Sons.

Flach G. P. and F. G. Smith III. 2013. Degradation of Cementitious materials associated with saltstone disposal units, SRNL-STI-2013-00118 Rev. 0. Aiken, SC: Savannah River Nuclear Solutions.

Garavito A.M., H. Kooi, and C.E. Neuzil, 2006. Numerical modeling of a long-term in situ chemical osmosis experiment in the Pierre Shale, Soth Dakota. Advances in Water Resources 29:481-491.

Gonçlavès. J. 2008. A slug test to assess the osmotic and hydraulics properties of argillaceous formations. Water Resources Research 44:W07501. doi:10.1029/2007WR006547.

Gonçlavès. J., P. Rousseau-Gueutin, G. de Marsily, P. Cosenza, S. Violette. 2010. What is the significance of pre pressure in a saturated shale layer? Water Resources Research 46:W04514. doi:10.1029/2009WR008090.

Graf, D.L., I. Friedman, and W.F. Meants. 1965. The origin of saline formation waters, 2 Isotopic fractionation by shale micropore systems. Geol. Surv. Cir. 393:32.

Hart M. L. 2013. Low head hyperfiltration through intact Burlington Limestone and Jefferson City Dolomite discs. Applied Geochemistry 33:357-365. 
Horseman. S.T., J.F. Harrington, and D.J. Noy. 2007. Swelling and osmotic flow in a potential host rock. Physics and Chemistry of the Earth 32:408-420.

Houben, G.J. and F. Wagner. 2007. Hyperfiltration of nickel sulphate solutions through silty sandstone and its effect on hydraulic conductivity. Applied Geochemistry 22:2029-2044.

Keijzer, Th.J.S., P.J. Kleingeld, and J.P.G. Loch. 1999. Chemical Osmosis in compacted clayey material and the prediction of water transport. Engineering Geology 53:151-159.

Malusis M.A., C.D. Shackelfor, and H. W. Olsen. 2001 A laboratory Apparatus to measure chemico-osmostic efficiency coefficients for clay soils. Geotechnical Testing Journal 24, no. 3:229-242.

Marine I.W. 1974. Geohydrology of the Buried Triassic Basin at the Savannah River Plant. Ground Water. 12:84-96.

Marine I.W. and S.J. Fritz. 1981. Osmotic model to explain anomalous Hydraulic Heads. Water Resources Research. 17:73-82.

Milling M. R and M. E. Denham. 2012. Background Water Table Chemistry in the General Separations Area, SRNL-13200-2012-00022. Aiken, SC: Savannah River Nuclear Solutions.

Neuzil, C.E. 2000. Osmotic Generation of 'anamolous' fluid pressures in geological environments. Nature 403:182-184.

Neuzil, C.E. and A.M. Provost. 2009. Recent experimental data may point to a greater for osmotic pressures in the subsurface. Water Resources Research 45:W03410. doi:10.1029/2007WR006450.

Richet C. 1992. Investigation of the migration of radionuclides in cement pastes, $\mathrm{PhD}$ Thesis. Paris XI University, France.

Saltstone osmotic pressure and its potential impact on contaminant movement,Task Technical Request HLW-SSF-TTR-2013-0004, Aiken, SCSavannah River Remediation.

Zhang S., Z. Qiu, W. Huang, J. Cao, ans X Luo. 2013 Characterization of a novel aluminumbased shale stabilizer. Journal of Petroleum Science and Engineering 103:36-40.

Valcke E., A. Marien, S. Smets, X. Li, N. Mokni, S. Olevella, X. Sillen. 2010. Osmosis-induced swelling of Eurobitum bituminized radioactive waste in constant total stress conditions. Journal of Nuclear Materials. 406:304-319. 


\section{Distribution:}

D. A. Crowley, 773-43A

T. O.Oliver, 773-42A

G. P. Flach, 773-42A

R. L. Nichols, 773-42A

K. L. Dixon, 773-42A

K. H. Rosenberger, 705-1C

S. P. Simner, 249-8H 